\title{
Social Exclusion -Its types and impact on Dalits in India
}

\author{
*Pradeep. B. Kadun, **Prof. Ravindra. D. Gadkar \\ "Research Scholar, Dept. of P.G.Studies\&Research in Social Work, Kuvempu University, \\ Shankarghatta, Shimoga (Dist) \\ ${ }^{* *}$ Professor, Dept. of P.G.Studies\&Research in Social Work, Kuvempu University, Shankarghatta, \\ Shimoga (Dist)
}

\section{Introduction}

"Social Exclusion" the term is very much use in the field of intellectuals and policy planners world wide for identifying the gaps for the development of the neglected people and the pertaining country. The causes for exclusion can vary from country to country in different times; reflecting deferent situation such geographically, historically and politically but the results will be the same in the form of lack of people development and the country. As a result of social exclusion, its impacts on the livelihood of the people such as increase in rate of poverty, health, and others. The exclusion is practiced world wide mostly on the identity of gender, caste, religion, ethnicity, color, race, nationality, and others. Social exclusion is a process which involves denial of rights and opportunities which the majority enjoy, resulting in the inability of individuals from excluded groups to participate in the basic political, economic and social functioning of the society, there by causing high human poverty and deprivation among them (S.Thorat.et) Social Exclusion is lack of access to resources and consequent inability to utilize them. It is further accentuated by denial of opportunities which enhance access to resources and their utilization. It can be experienced by anyone who is in position which is vulnerable to such impeding conditions. Amartya $\operatorname{Sen}(2000)$ has pointed out that the historical roots of the concept of social exclusion goes back as far as Aristotle. But the contemporary term emerged as a result of social unrest due to increasing unemployment and economical inequalities in France during 1960s and it was adopted particularly by the U.K new labor government elected in the late 1990s when the ILO also took a lead in driving the concept to less economically developed countries(Jane Mathieson.et) there is a lack of theoretical and empirical studies on the concept of social exclusion based on caste, religion ethnicity the types of exclusion and the indicators of the exclusion and its impact on the excluded groups. The paper wants to discuss about the Dalits of India in the below mentioned frame work of social exclusion.

\section{Meanings of Social Exclusion in Different Countries}

Definitions from ILO country case studies (Gore \& Figueiredo,1997:17-18)

Peru: "social exclusion is the inability to participate in aspects of social life considered important. These are economic, cultural and political."Hardcore" social exclusion occurs when there is mutual feedback, rather than offsetting, relationships between the inabilities to participate in these three dimensions of social life'

India: 'social exclusion is the denial of the basic welfare rights which provide citizens positive freedom to participate in the social and economic life and which thereby render meaningful their fundamental negative freedoms'.

Thailand: 'social exclusion is a process through which citizenship rights on which livelihood and living standards depend are not recognized and respected. This involves relationships between people, in which rights are challenged and defended through negotiations and conflict'.

Russia: 'social exclusion is both an objective and a subjective feature of people's lives. As an objective condition, it is characterized by material deprivation and infringement of social rights (including rights related to employment for the employed and the unemployed). As a subjective

Feeling, it is characterized by a sense of social inferiority in the community or a loss of prior social status'.

Tanzania: 'social exclusion is both a state and a process. As a state, it is equivalent to relative deprivation; as a process, it refers to the socially determined structures and processes which impede access on the part of some members of society to economic resources, to social goods, and to institutions which determine their destinies'. Yemen: 'social exclusion is the opposite of social integration. It is present when some individuals and groups cannot participate, or are not recognized, as full and equal members of society, at local community or national level'. 


\section{The concept of social exclusion}

Social exclusion is defined as social process which involves denial of fair and equal opportunities to certain social groups in multiple spheres in society, resulting in the inability of individuals from excluded groups to participate in the basic political, economic and social functioning of the society. (S.Thorat,et) Social Exclusion is mainly a group concept, Amartya sen say the situation were some people are kept out, and were some people are being included and describes two situations as unfavorable exclusion and unfavorable inclusion. The acts of exclusion which excludes people from having an access and entitlement to certain social groups that are based on the recognized and accepted principles, rules, norms, practices of fairness can be considered as unfair exclusion, similarly the inclusions which provide access and entitlement to persons from certain social groups but on different terms and conditions can be termed as unfair inclusion.(sen) there is a differentiation in individual exclusion and group exclusion. A groups which are wholly or partially excluded on the base of their identity from full participation in society and having a two dimension as "societial relations" causing exclusion and their "out comes" causing deprivation(S.thorat). Adam smiths focus on the deprivation involved in not "being able to appear in public without shame" is a good example of a capability deprivation that takes the form of social exclusion. Sen defines active and passive exclusion. As the deliberate exclusion of people from opportunities through government policies or other means is called active exclusion, were as the passive exclusion works through the social process in which there are no deliberate attempts to exclude, but never the less may result in exclusion of people from a set of circumstances. The concept of social exclusion can be applied with the Indian context were caste and untouchability is been practiced from centuries ago and its changes from time to time.

\section{Social Exclusion in Indian context.}

In India social exclusion is practiced on the base of caste and untouchability based exclusion were a group of people being excluded or denial of the rights and opportunities which the majority enjoys. According to the valid text of India the society is divided in to four varans or the division of group of people on the base of their birth such as the chaturvarnya or the division of the society in to four classes a hierarchy based the Brahmins should cultivate the knowledge, that the kshatriya should bear arms, the vaishya should trade and the shudra should serve all the above three classes.(Ambedkar 1944) The Brahmin flattered the Kshatriya and both let the Vaishya live-in order to be able to live upon him. But the three agreed to beat down the Shudra. He was not allowed to acquire wealth lest he should be dependent of the three Varnas. He was prohibited from acquiring knowledge lest he should keep a steady vigil regarding his interests. He was prohibited from bearing arms lest he should have the means to rebel against their authority. That this is how the Shudras were treated by the Tryavarnikas is evidenced by the Laws of Manu. According to (Manusmriti) A Brahman is purified by water that reaches his heart, a kshtriya is purified by water that reaches his throat, a vaishya by water taken in to his mouth and a shudra by water touched with the extremity (of his lips) Let him ask a Brahman on meeting him after (his health with the word)kushala, a ksthriya with a word anamaya a vaishya with a word khsma and a shudra with a word anarogya.

Due to chaturvarnya the shudras could not receive education, they could not think out or know the way to their salvation they were condemned to be lowly and not knowing the way of escape and not having the means of escape they became reconciled to eternal servitude, which they accepted as they inescapable fate.(Ambedkar 1944) this is what according to adam smith capability deprivation is called.

\section{Caste and untouchablity based social exclusion in contemporary India}

Even today the Indian society is following the same varna system were the society is categorized in to four namely the Brahmans, kshtriya, vaishya, and the shudra and the practice of the varna system is still in existence which has a practice of discriminating the shudras. . Today in contemporary Indian society the shudras are known as the dalits which is a Marathi word means as "broken men" and presently there are 180 million Dalits categorized and classified as scheduled castes in the Indian constitution. How ever more than 180 million Dalits are subjected to social, economical, political and cultural exclusion deeply imbedded in social practices. Dalits are social and physically separate they most live in outside areas of the village in rural areas and in specified areas in cities. They are denied basic human rights not allowed to own property rights and to use public and common property such as the wells, tanks and temples. After India's independence when India declared itself as a democratic nation having adopting a written constitution in which the practice of social exclusion in the form of untouchability is been eradicated and made it as a punishable offence under article 17 and 18 of the Indian constitution and have made several developmental provision for the Dalits. In spite of this the practice of social exclusion and discrimination has been practiced in one or the other form the practice still exists in a newer forms and strategies. 


\section{Types and indicators of social exclusion}

Types of exclusion

Caste based exclusion: the caste system is based on the division of people in to social groups in which civil, cultural and economic rights of each individual caste are predetermined or ascribed by birth and made hereditary. The assignment of civil, and economic rights is, unequal and hierarchical and the most important feature is it provides for regulatory mechanism to enforce social and economic organizations through the instruments of social ostracism and the caste system is reinforced further with justification and support from philosophical elements in the Hindu religion.(Ambedkar 1936 ) caste at the top of the social order enjoys more rights at the expense of those located at the bottom of the caste hierarchy and have fewer economic and social rights.

Untouchability based social exclusion : the untouchables who are at the bottom of the caste hierarchy suffered the most from unequal assignments and entitlements of rights. The untouchables suffered from social exclusion and discrimination involving certain rights which include civil, cultural, religious and economic rights.and particularly the notion of untouchability, which is unique to the untouchable caste only they are considered impure and polluting and unfit for social association and inter relation with castes above.

\section{Indicators of social exclusion.}

The indicators of social exclusion can be traced by a suitable situation described by Dr Ambedkar in his paper "Annihilation of caste" in which he points that under the rule of Peshwas in Maratha country the untouchables were not allowed to use the public streets if a Hindu was coming along lest he should pollute the Hindu by his shadow the untouchable was required to have a black thread either on his wrist or neck as a sign or a mark to prevent the Hindus from getting themselves polluted by his touch through mistake. In Poona the capital of Peshwas the untouchable was required to carry, strung from his waist, a broom to sweep away from behind the dust he treaded on lest a Hindu walking on the same should not be polluted. In poona the untouchables was required to carry an earthen pot, hung in his neck were ever he went for holding his spit lest his spit falling on the earth could pollute a Hindu who might unknowingly happen to tread on it.

Socially :the exclusion is based on caste untouchability such as the excluded member of a community do not have the right to entry a public places like temples, schools, hospitals, housings, etc.restruction on entry of various educational institution, unequal treatment in teaching. The untouchables are made to practice some identifiable cultural practices separate from the society such that they have their separate gods, marriage system, the crimination system and different food culture from the other people of the society.

In economic spheres : denial of equal rights and opportunities to the low caste groups, assets like agricultural lands and non land assets employments social needs like education, health, housing and others which leads to lower income and high poverty among the Dalits. in economical exclusion practice the Dalits or the members of excluded group are denied for jobs, and in agricultural through denial of purchase and sale, lower wages paid for Dalits , in credit markets were the Dalits has to pay high interest for the loans taken.

Education: discriminations in schools take the form of denial of access to education and the skill development among the Dalits children. This reduces the quality of human resources and reduces the employability for quality jobs and force them to fall back on low earning manual wage labor in farming and non farming activities. Denial of education leads to high rate in illiteracy, low functionally literacy and high dropout rates and limited skill development, discrimination in education may cause high representation in menial jobs, low wages, low income and ultimately high poverty.(SThorat.et)

\section{Health facilities:}

Through denial of admission in the primary health centre through discriminatory access to primary health centers and private health providers which may take following forms.

Denial of visiting to Dalits home, denial of giving information about health facilities, , lack of care leading to requirement of private medical attention and loss of income, delay in complication delivery leading to private medical attention (S.Thorat.et)

Political spheres: were the Dalits are denied to practice they political rights such as rights and means to participate in the exercise of political powers and denial of justice, freedom of expression, rule of law .The constitution of India has made certain provision to empower the Dalits politically but the exclusion has made them to think for political participation.

Giving representation to the weak candidates from the Dalits community for election by pertaining political parties. Actually at the reserved political constituency were the deciding people will not be the Dalits himself but the upper caste voter who propously elect a candidate who can represent the upper caste not for the Dalits. Due to this the Dalits can't elect they representative who can participate on their behalf in the policy making. 


\section{Impact of exclusion on Dalits.}

The impact of exclusion has made the Dalits as vulnerable community since from the vedic time. The process of social exclusion system has made the Dalits dependable on the others so called upper communities. In the contemporary scenario due to the impact of exclusion of Dalits they are subjected to social, economically and politically exclusion.A study of 2006 on untouchables rural in India covering 565 villages in 11 states has revealed the extent to which untouchablity and social exclusion is practiced in spite of officially banned by the constitution of India.(the data below mentioned is taken from sc/st commissions report, New Delhi)

\section{In government services}

In spite of constitutional mandate for social justice various local institution in India facilitates and practice untouchablity

37.8\% of the villages Dalits students are made to sit separately in government schools.

$27.6 \%$ of the village's Dalits are prevented from entering police stations.

$\mathbf{2 5 . 7 \%}$ of the village Dalits are prevented from entering ration shops.

$33 \%$ of the village public health workers refuse to visit Dalits homes.

$\mathbf{1 4 . 4 \%}$ of the village Dalits are not permitted to enter panchayat building.

$\mathbf{1 2 \%}$ of the village Dalits is forced to form separate lines at polling booths.

$\mathbf{4 8 . 4 \%}$ of the Dalits are denied to access to water sources.

In market access

$\mathbf{3 5 \%}$ of village Dalits banned from selling produced in local market.

$47 \%$ of village milk cooperatives prevent Dalits from selling milk and $25 \%$ from buying milk.

In work.

$\mathbf{2 5 \%}$ of village Dalits paid lower wages than non dalits,work longer hours and have more delayed wages and suffer from verbal and physical abuse.

$\mathbf{3 7 \%}$ of the village Dalits workers paid wages from a distance to avoid physical contact.

\section{In religion and rites}

$\mathbf{6 4 \%}$ of Dalits restricted from entering Hindu temples.

$\mathbf{5 0 \%}$ of village Dalits prevented from accessing crimination grounds.

\section{In private spheres}

$\mathbf{7 3 \%}$ of village's Dalits not permitted to enter non-Dalits homes.

$\mathbf{3 5 . 8 \%}$ of Dalits denied entry in to village shops.

\section{Crimes against Dalits}

According to official Indian crime statistics averaged over the period 2001-2005.

27 atrocities against Dalits every day.

13 Dalits murdered every week.

5 Dalits homes burnt every week.

6 Dalits kidnapped or abducted every week.

3 Dalits women raped every day.

11 Dalits beaten every hour and A crime committed against a Dalits every 18 minutes

\section{Conclusion:}

From the foregoing discussion it may concluded that the concept of social exclusion is a process of blocking the development of the marginalized communities disintegrating people and communities in to mainstream of development, with a series of institutionalized social systems. The most affected population is Dalits who lag in all spheres of developmental activities. Dr .Ambedkar therefore with his visionary mission provided a comprehensive framework for development of people in general and Dalits in particular.

\section{References:}

[1]. Ambedkar.B.R.(1944) Annihilation of caste. Dept.of education.Govt. of Maharastra.

[2]. Sen, Amartya.(2000) Social Exclusion: Concept, Application and Scrutiny. Social Development Paper.o1

[3]. Thorat.S.K,and Sadhan Nidhi (2009) Caste and Social Exclusion Issues Related to Concept, indicators and Measurements. EPW.44.

[4]. Mathieson.J and etl . . (september 8). Meaning,Measurements and Experience and links to health inequalities. WHO Social Exclusion Knowledge Network Background Paper .

[5]. Kasi, K. Z. (2009). Dimensions of Social Exclusion. Cambridge Scholars Publishing .

[6]. Kabeer Naila. (n.d.). Social exclusion: concepts, findings and implications for the MDGs.

[7]. Nayar, K. R. (octomber 2011). India's country experience in addressing social exclusion in maternal and child health. World Health Organization for the World Conference on Social Determinants of Health

[8]. Banerjee, Biswajit and J B Knight (1985): 'Caste Discrimination in Indian Urban Labour Market', Journal of Developing Economics. 
[9]. Deshi, A K and H Singh (1995): 'Education, Labour Market Distortions and Relative Earning of Different Religious-Caste Categories in India', Canadian Journal of Development of Studies, December 21.

[10]. Khan, Mumtaz Ali (1995): Human Rights and the Dalits, Uppal Publishers, Delhi.

[11]. Lal, Deepak (1988): The Hindu Equilibrium, Clarendon, Oxford.

[12]. Moon, Vasant (1987): Dr Babasaheb Ambedkar: Writings and Speeches, Volume3, 1,Government of Maharashtra.

[13]. Parvathamma (1984): Scheduled Castes and Tribes: A Socio-Economic Survey, Ashish, Delhi. Report of the Commissions for SC/ST (1998): Commission for SC/ST, Gol, Delhi.

[14]. Shah, Ghanshyam (1998): 'Caste and Un-touchability: Theory and Practice', paper presented at seminar' Ambedkar in Retrospect', Jawaharlal Nehru University, Delhi. 